\title{
Mapping-by-sequencing accelerates forward genetics in barley
}

\author{
Martin Mascher ${ }^{\dagger}$, Matthias Jost ${ }^{\dagger}$, Joel-Elias Kuon, Axel Himmelbach, Axel Aßfalg, Sebastian Beier, Uwe Scholz, \\ Andreas Graner and Nils Stein ${ }^{*}$
}

\begin{abstract}
Mapping-by-sequencing has emerged as a powerful technique for genetic mapping in several plant and animal species. As this resequencing-based method requires a reference genome, its application to complex plant genomes with incomplete and fragmented sequence resources remains challenging. We perform exome sequencing of phenotypic bulks of a mapping population of barley segregating for a mutant phenotype that increases the rate of leaf initiation. Read depth analysis identifies a candidate gene, which is confirmed by the analysis of independent mutant alleles. Our method illustrates how the genomic resources of barley together with exome resequencing can underpin mapping-by-sequencing.
\end{abstract}

\section{Background}

The recent profound transformation of molecular biology by next-generation sequencing (NGS) technologies [1] and the ready availability of reference genome sequences [2] has enriched the plant geneticist's toolbox with what Schneeberger and Weigel named 'fast-forward genetics' [3]. Combining classical bulked-segregant analysis [4] with aligning NGS read data to a reference genome has made gene cloning essentially a single-step computational procedure once a mapping population has been established [5]. Within a few days' time, mapping intervals can be delineated in silico and mined for likely candidate genes, deprecating marker saturation, and physical mapping of the target interval. Since its original implementation as ShoreMap in an $\mathrm{F}_{2}$ population of Arabidopsis thaliana, mapping-by-sequencing has been extended to other population types such as isogenic backcross populations $[6,7]$ as well as to other plant and animal species such as rice [8], maize [9], mouse, and zebrafish [10].

All successful attempts at mapping-by-sequencing in these species could take advantage of high-quality mapbased reference sequences. A reference genome embeds almost all genes of a species in a genomic context, a crucial prerequisite for mapping-by-sequencing, as sequencing of phenotypic bulks provides only allele frequencies

\footnotetext{
* Correspondence: stein@ipk-gatersleben.de

${ }^{\dagger}$ Equal contributors

Leibniz Institute of Plant Genetics and Crop Plant Research (IPK), OT

Gatersleben, Corrensstraße 3, 06466 Stadt Seeland, Germany
}

at variant positions, but no genotypic data that could be used to construct a genetic map de novo to infer marker order. How this order can be derived in the absence of a reference genome and how rapid NGS-based gene isolation may be implemented in species for which only draft genome assemblies are available is not obvious. Galvao et al. [11] have proposed the collinear gene order in related species as a proxy for gene order in species without a reference genomes, but have also noted that this synteny-based approach may adversely affect mapping resolution. A novel bioinformatical procedure to find causal mutations by whole genome sequencing without using positional information has been applied to find causal variants in plant species with small genomes [12].

In addition to its importance for agriculture, barley (Hordeum vulgare L.) has been a model organism of genetics throughout the 20th century and boasts excellent resources for forward genetics. A large number of barley mutants had been created from the 1940s to the 1970s when mutation breeding programs flourished [13-16]. These mutant lines have been classified phenotypically and are nowadays maintained and distributed by seed banks. To further support the utilization of these resources in research and breeding, 881 original mutants have been backcrossed to cultivar (cv.) Bowman as a recurrent parent to obtain mutant alleles in a nearly isogenic background. Array-based genotyping of these introgression lines confirmed and broadly delimited introgression 
intervals [17]. This legacy of half a century of meticulous research has been recently complemented by several mutant populations $[18,19]$ that were obtained in a systemic way via mutagenesis with ethyl methanesulfonate (EMS) to empower reverse genetics.

In this regard, the mutants of barley have been instrumental in confirming candidate genes discovered through mapping in bi-parental populations [20] or association panels [21]. However, the full exploitation of the allelic diversity captured in these resources for basic research and crop improvement has been impeded by the lack of a reference genome sequence of barley. The major obstacles in assembling the barley genome are its sheer size $(5 \mathrm{~Gb})$ and its high content of repetitive DNA (80\%), which pose a heavy sequencing load and put a challenge for current assembly algorithms [22]. Boosted by the enormous increase in sequencing throughput, extensive sequence datasets have accumulated recently and have been integrated with a genome-wide physical map and high-density genetic maps [23]. A large fraction of low-copy portion of the barley genome is now represented by contigs of a whole-genome shotgun assembly which are positioned with a resolution of approximately $3 \mathrm{cM}$ [24]. Moreover, an exome capture assay designed on the basis of the annotated sequence assembly has made approximately $60 \mathrm{Mb}$ of mRNA-coding sequence accessible to cost-efficient high-throughput resequencing [25].

To date, the complex sequence framework of barley has not been used as a backbone for mapping-bysequencing. Though the hopes are high, concerns remain that the fragmentary and incompletely ordered structure of the sequence assembly and the only partial representation of the gene complement may stall fastforward genetics. Leveraging the physically and genetically anchored sequence assembly, exome sequencing and the extensive mutant collections available to the barley research community, we put mapping-by-sequencing to the test in barley and were able to rapidly identify a gene underlying the many-noded dwarf (mnd) phenotype.

\section{Results}

\section{mnd mutant phenotype}

The original mnd mutant was generated by X-ray mutagenesis at our institute in the 1950s [13]. The most conspicuous characteristic of mnd plants is their shortened plastochron, that is, a faster rate of leaf initiation. $\mathrm{Mu}$ tants have on average two times more leaves than wildtype plants as a result of a faster emergence of leaves (Figure 1). Moreover, culm internode lengths are decreased in the mutant. Despite the larger number of internode (eight to nine in the mutant versus four to five in the wildtype), plant height is reduced by about one third under field conditions, but not in the greenhouse
(Figure 1d). Apart from spacing, also the shape of leaves is altered in the mutant: leaves are narrower and more erect compared to the wildtype. Additional characteristics of $m n d$ are an increased number of tillers (vegetative shoot branches arising from lateral meristems) and shorter spikes (Figure 1b; Additional file 1: Figure S1).

\section{Allele frequency mapping}

We adopted a strategy similar to the ShoreMap [5] and MutMap [8] methods that inspect the genome-wide distribution of allele frequency in phenotypic bulks of an $\mathrm{F}_{2}$ population developed by outcrossing the mutant to a wildtype genotype (Additional file 2: Figure S2). Progeny of a cross between an mnd plant with a wildtype plant of cultivar (cv.) Barke was selfed to obtain an $\mathrm{F}_{2}$ population of 100 individuals. The mnd allele segregated in this population as a monogenic recessive trait $(19 \mathrm{mu}-$ tants, 81 wildtype plants, $\chi^{2}=1.92, P$ value $\left.=0.17\right)$. DNA from 18 mutant plants and 30 randomly selected wildtype plants was combined into two pools, which were subjected to exome capture and subsequent high-throughput sequencing on the Illumina HiSeq2000, yielding 82 million and 70 million $2 \times 100 \mathrm{bp}$ read pairs for the mutant and wildtype pools, respectively. Reads were mapped onto the whole-genome shotgun (WGS) assembly of cv. Barke [23] and single nucleotide polymorphisms (SNPs) were detected. The visualization of allele frequencies at SNP positions along the physical and genetic map of barley revealed a single sharp peak on the long arm of chromosome $5 \mathrm{H}$, where the frequency of the mutant allele increased to over $95 \%$ and dropped to about $30 \%$ in the wildtype pools (Figure 2a). Note that the ratio between the number of plants that are heterozygous at the mnd locus and the number of those that are homozygous for the wildtype allele is expected to be 2:1 in the wildtype bulk. Selected SNPs in the interval of 80 to $110 \mathrm{cM}$ in the map of [21] were converted to single marker assays (Additional file 3: Table S2). Genetic mapping in the $F_{2}$ population confirmed these markers to be tightly linked to the mnd phenotype (Figure 2b).

\section{Read depth analysis identifies a likely candidate gene}

As X-ray mutagenesis commonly induces large deletions [26], we queried our sequence data for exome capture targets that are covered by sequence reads in the wildtype pool, but not in the mutant pool. As gene models and exome capture targets are given as coordinates on the WGS assembly of cv. Morex, reads were mapped again onto this assembly and read coverage was calculated at each base position and averaged across contiguously covered intervals corresponding to capture targets. Marker assays revealed that we had erroneously included one heterozygous plant in the mutant bulk, which was confirmed by phenotypic analysis of the corresponding 

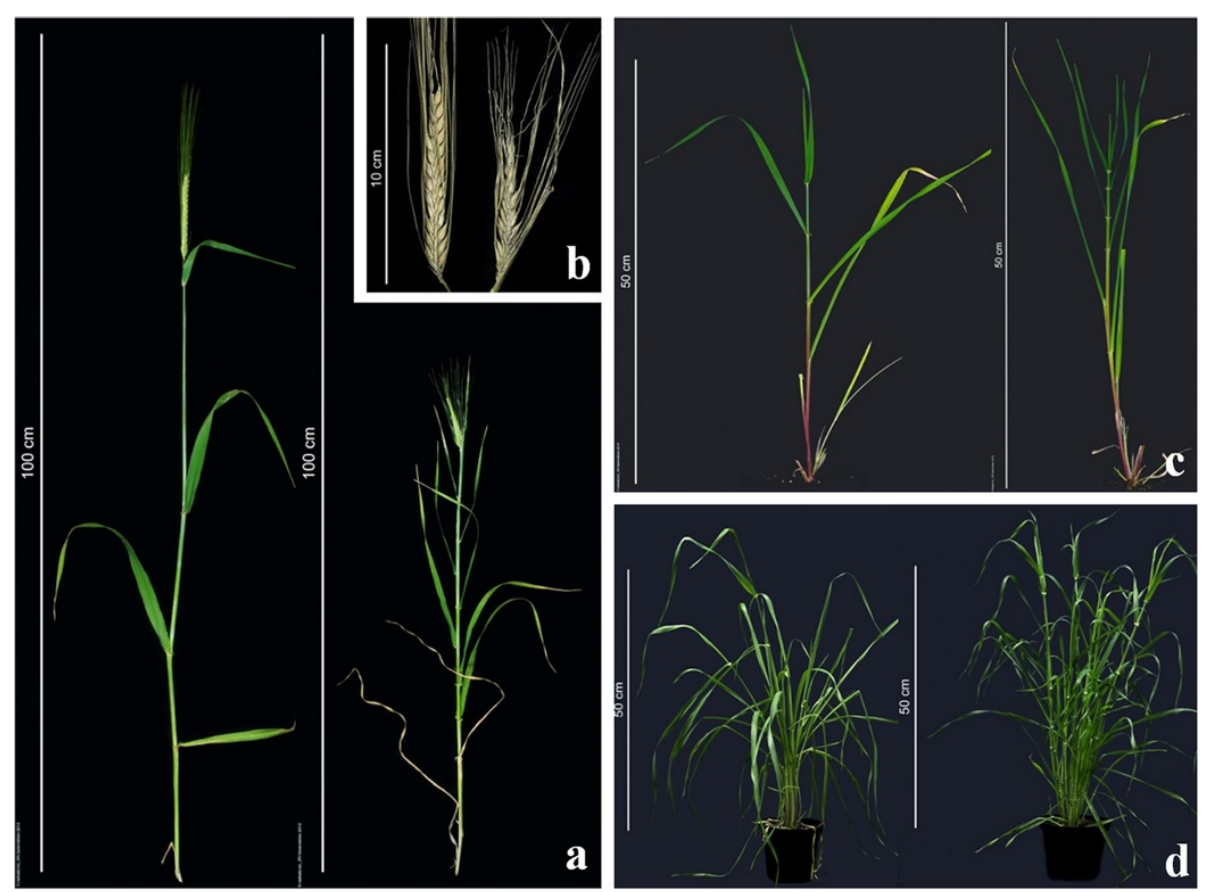

Figure 1 Phenotypic characteristics of $\boldsymbol{m n d}$ plants. (a) Mutants (right) have a significantly higher number of nodes compared to the wildtype (left) and show a semi-dwarf growth habit. (b) Ear length is reduced under field conditions (left: wildtype, right: mutant). (c) Leaf formation in early developmental stages is faster in mnd plants (right) compared to the wildtype (left). (d) Mutant plants (right) grown under greenhouse conditions have more internodes without a dwarfing phenotype. The wildtype is shown to the left.

$\mathrm{F}_{3}$ family. Thus, we expected a small number of sequence reads at the mnd locus in the mutant pool originating from the single heterozygote. At genome scale, we identified 435 intervals (whole genome shotgun sequence contigs carrying the respective exome capture targets) that were at least $150 \mathrm{bp}$ and fulfilled our rather relaxed criteria for potential deletions (Additional file 4: Table S3). Of these targets, 18 were mapped by POPSEQ [24] to the broadly defined interval $(5 \mathrm{H}, 80 \mathrm{cM}$ $110 \mathrm{cM}), 278$ were mapped to other regions of the genome and 139 were unmapped. Out of all 435 intervals, 48 were located on contigs of the WGS assembly of cv. Morex [23] with high-confidence genes predicted on. All but two of these genes had a functional annotation. Among the contigs carrying putatively deleted capture targets and localized to our target interval, six carried high-confidence genes (Figure 2b, Table 1). One of these, contig 49382 was anchored at $96 \mathrm{cM}$ in the POPSEQ map [24] and thus closest to the allele frequency peak (97\%) in the mutant bulk at $97 \mathrm{cM}$ (Additional file 5: Table S1). Moreover, contig 49382 harbored two putatively deleted regions, among them the longest detected interval. Note that a single large deletion would rather show up as several smaller deleted target intervals because exome capture targets only disjoint exons, and introns are represented neither in the mutant nor the wildtype. The deleted regions on contig 49382 overlapped with the two exons of the high-confidence gene MLOC_64838.2 annotated as 'Cytochrome P450' (Figure 2c). This gene was the only gene predicted on contig 49382. A BLAST search of the protein sequence against the rice and Arabidopsis genomes identified members of the CYP78A family of cytochrome P450 enzymes. One of these genes, rice CYP78A11, is known as PLASTOCHRON1 (PLA1) [27]. As the rice pla1 phenotype (rapid leaf initiation, reduced leaf size, and plant height) closely resembles barley mnd, we considered MLOC_64838.2 as a promising candidate.

\section{Mutant analysis confirms MLOC_64838.2 as HVMND}

PCR amplification of the candidate succeeded in cultivars Morex and Barke, but failed in the mutant MHOR474. By contrast, we were able to amplify genes that were predicted to be close to MLOC_64838.2 through collinearity to the model grass Brachypodium distachyon [28] and were anchored genetically within the mapping interval. Screening of our TILLING (Targeting Local Lesions IN Genomes) population [18] identified 20 EMS mutants with synonymous and 17 mutants with non-synonymous changes. One mutant carrying a SNP (G261A) that led to a premature stop codon in heterozygous state (Table 2) was selected to check the phenotypic effects. Among the 


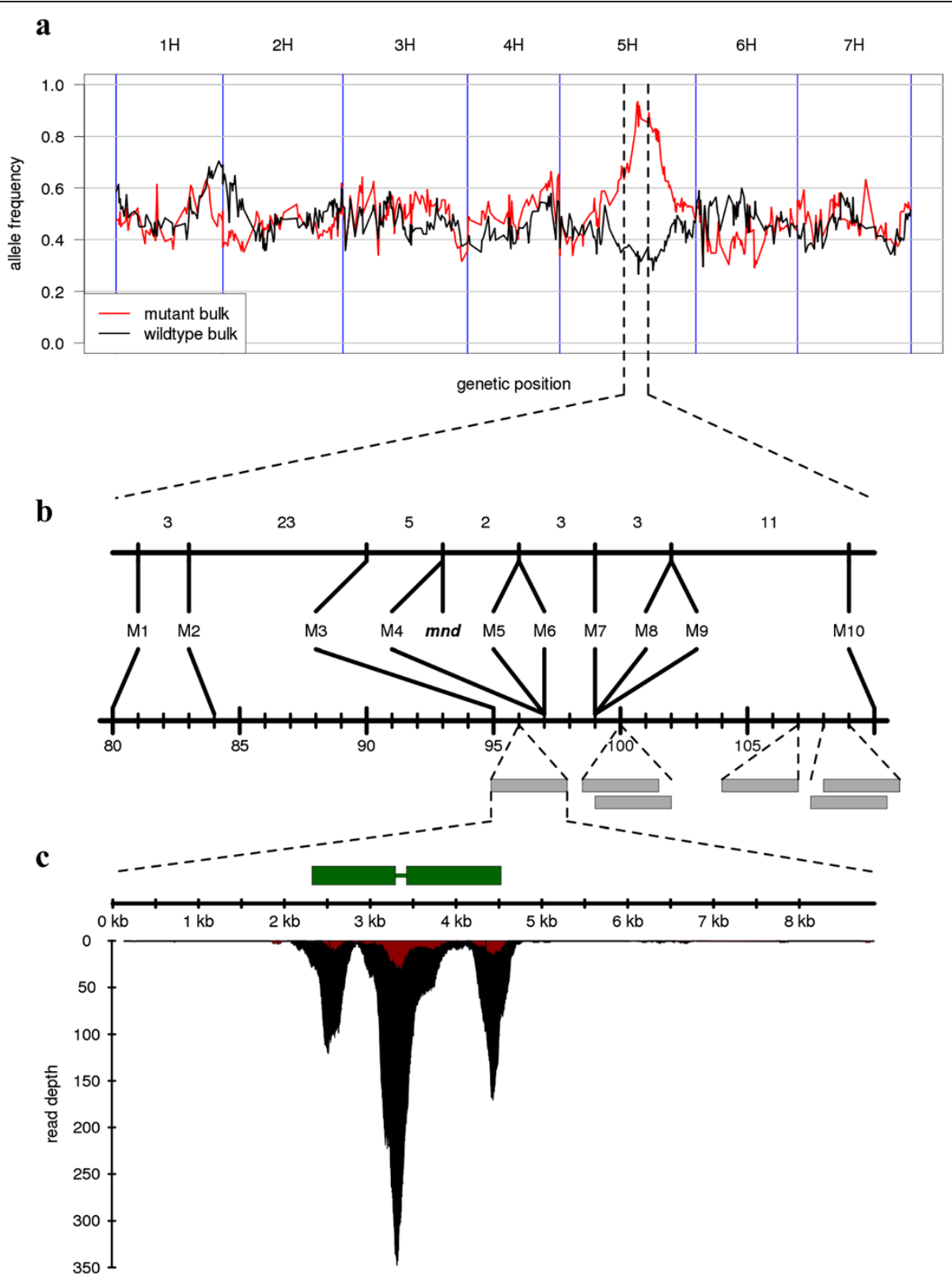

Figure 2 Mapping-by-sequencing. (a) The frequency of the alternate allele relative to the Barke reference in the two capture pools is visualized along the integrated physical and genetic map of barley [23]. (b) Ten SNPs from the target intervals were converted to CAPS markers and genotyped on the entire $F_{2}$ mapping population. The number of recombinants between the markers (top axis) and marker positions in genetically anchored WGS assembly [24] (bottom axis) are indicated. Sequence contigs carrying large (>150 bp) putative deletions are shown as gray rectangles. (c) Read depth of MND (MLOC_64838.2) in the two capture pools. The positions of the two exons of MND in WGS contig 49382 are shown as green rectangles. At the bottom, the number of sequence reads per base position is shown for the mutant pool (red) and the wildtype pool (black). Because of a single heterozygous plant that was erroneously included in the mutant bulk, MND is also present at low read coverage in the mutant pool. Note that the highest coverage peak is in the short intron (130 bp) of MND due to a higher number of redundant capture probes at the ends of the two exons.

offspring of this plant, 15 plants were heterozygous, two were homozygous for the wildtype allele and five were homozygous for the mutant allele. All of the homozygous mutant plants (and only these) showed a significantly increased number of internodes, characteristic of the mnd phenotype (Figure 3a,b). Furthermore, introgressions of two Bowman nearly-isogenic lines characterized as mnd (BW520 and BW522) had been mapped to chromosome arm 5HL previously [17]. Sanger sequencing of MLOC_64838.2 in BW520 revealed one non-synonymous SNP in the coding sequence. The gene could not be amplified in BW522, whereas all syntenic genes were present 
Table 1 Deleted target regions within the genetic target interval $(5 \mathrm{H}, 80 \mathrm{cM}-110 \mathrm{cM})$

\begin{tabular}{|c|c|c|c|c|c|c|c|}
\hline $\begin{array}{l}\text { Morex WGS } \\
\text { contig }\end{array}$ & $\begin{array}{l}\text { Start } \\
\text { position }\end{array}$ & $\begin{array}{l}\text { End } \\
\text { position }\end{array}$ & $\begin{array}{l}\text { Coverage }^{a} \\
\text { mutant }\end{array}$ & $\begin{array}{l}\text { Coverage }^{a} \\
\text { wildtype }\end{array}$ & $\begin{array}{l}\text { HC confidence } \\
\text { genes }[23]\end{array}$ & $\begin{array}{l}\text { Functional } \\
\text { annotation [23] }\end{array}$ & $\begin{array}{l}\text { Genetic position } \\
\text { (POPSEQ) [24] }\end{array}$ \\
\hline contig_49382 & 2,107 & 2,455 & 0.4 & 24.4 & MLOC_64838.2 & Cytochrome P450 & $5 \mathrm{H}, 96.6 \mathrm{cM}$ \\
\hline contig_49382 & 3,871 & 4,101 & 1.1 & 8.8 & MLOC_64838.2 & Cytochrome P450 & $5 \mathrm{H}, 96.6 \mathrm{cM}$ \\
\hline contig_159829 & 785 & 996 & 0.9 & 8.2 & MLOC_21734.1 & CC-NBS-LRR & $5 \mathrm{H}, 99.9 \mathrm{cM}$ \\
\hline contig_159829 & 4,501 & 4,709 & 0.4 & 12.4 & MLOC_21734.1 & CC-NBS-LRR & $5 \mathrm{H}, 99.9 \mathrm{cM}$ \\
\hline contig_1558349 & 1,236 & 1,477 & 1.5 & 11.5 & MLOC_10070.1 & MATE efflux family & $5 \mathrm{H}, 99.9 \mathrm{cM}$ \\
\hline contig_45126 & 14,800 & 14,961 & 0.8 & 7.3 & AK365660 & $\begin{array}{l}\text { Tumor susceptibility } \\
101 \text { protein }\end{array}$ & $5 \mathrm{H}, 107.1 \mathrm{cM}$ \\
\hline contig_2547452 & 4,712 & 4,913 & 0.1 & 10.5 & AK357178 & $3^{\prime}-5^{\prime}$ exoribonuclease CSL4 & $5 \mathrm{H}, 108.1 \mathrm{cM}$ \\
\hline contig_58347 & 7,926 & 8,186 & 1.0 & 14.5 & MLOC_70680.1 & DNA repair protein-like & $5 \mathrm{H}, 109.4 \mathrm{cM}$ \\
\hline
\end{tabular}

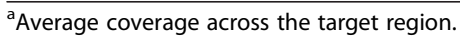

(Table 3). We ordered 37 mutant accessions from the Nordic Gene Bank (NordGen) that were described as mnd. Resequencing of our candidate in these lines revealed four amino acid changes, 16 premature stop codons, one disruption of a splice site, one 107 bp deletion in the second exon, and six complete deletions (Additional file 6: Table S4). When grown in the greenhouse, all mutants showed the mnd phenotype (Figure 3c-e). We considered this large number of molecular lesions found in several independent mutant collections as conclusive evidence that loss-of-function of MLOC_64838.2 underlies the $m n d$ phenotype and named this gene as $H v M N D$.

\section{MND is a member of the CYP78A subfamily of cytochrome P450 enzymes}

MND is a member of the CYP78A family of cytochrome P450 enzymes. We found four CYP78A genes in the whole genome shotgun assembly of barley (Figure 4). Though the mnd phenotype mimics pla1, MND is not an ortholog of PLA1. The ortholog of MND in rice, Os09g09g3594, is located in a syntenic region on rice chromosome 9 [28] and shows 75\% identity with MND on the protein level. PLA1 does not have a clear ortho$\log$ in barley (Figure 4), but has approximately 54\% amino acid sequence identity to MND and two other CYP78A genes, MLOC_68312.1 and MLOC_68718.1. As PLA1 has orthologs in maize and Arabidopsis (Figure 3), an ancient ortholog of PLA1 might have been lost in the Poaceae lineage after its split from rice and maize. In line with this hypothesis, we did not find PLA1 orthologs in barley, the wheat progenitors, T. urartu and Ae. tauschii, and B. distachyon.

We looked up the expression profile of $H v M N D$ and other barley genes of CYP78A family in the eight tissues examined by The International Barley Genome Sequencing Consortium [23]. Expression of CYP78A genes was found across all tissues, with different genes of the family being most abundant in different tissues (Figure 5).
Among the four CYP78A genes, $H v M N D$ was the most ubiquitous, being expressed in all samples, although only weak expression was detected in developing grains 15 days after anthesis.

\section{A physical map of the mnd locus}

There may be concerns as to the general applicability of our strategy to other map-based cloning projects. The isolation of MND was facilitated by the facts that its homolog PLA1 in the model species rice is well characterized and that the phenotype of PLA1 knockout mutants mirrors mnd. If, moreover, MND had not been represented in the exome capture target space, no obvious candidate could have been pinpointed. In this case, the distribution of allele frequency confirmed by genetic mapping of markers developed from in silico variants would have only delimited a target interval to be subjected to further scrutiny. As was proposed earlier, the genome-wide physical map of barley should principally obviate the need of constructing local physical maps by map-based cloning to delimit candidate genes [29]. BAC survey sequence data associated with the physical map of barley [23] can be used to associate marker sequences or candidate genes with physical contigs, whose minimum tiling paths [29] can then be sequenced. Thus it was our intention to test whether the information provided by the bulked-segregant sequencing experiment was sufficient to select a physical contig of the genomewide physical map for delimitation of the target locus region and identification of a candidate gene.

We put this strategy into practice to retrieve the physical map around the MND locus (Figure 6). The major steps towards this aim were the identification of BAC contigs of the barley genome physical map harboring MND as well as its flanking markers, sequencing the minimum tiling paths (MTPs) of these contigs and perform integrative sequence analysis to predict gene models on the BAC sequence assemblies. First, we 
Table 2 TILLING mutants

\begin{tabular}{|c|c|c|c|}
\hline Plant \# & $\mathrm{SNP}^{\mathrm{a}}$ & M3 status & Effect $^{b}$ \\
\hline 13339_1 & С160T & Heterozygote & P54S \\
\hline 6869_1 & С180T & Homozygote & $L 60=$ \\
\hline 4098_1 & G261A & Heterozygote & W87* \\
\hline 3895_1 & G306A & Homozygote & $\mathrm{R} 102=$ \\
\hline 4642_1 & G435A & Heterozygote & M145I \\
\hline 6631_1 & G465A & Heterozygote & $\mathrm{R} 155=$ \\
\hline 4555_1 & G468A & Heterozygote & $E 156=$ \\
\hline 9906_1 & С609T & Heterozygote & $S 203=$ \\
\hline 13573_1 & G639A & Homozygote & Q213= \\
\hline 7036_1 & $\mathrm{C} 657 \mathrm{~T}$ & Heterozygote & $S 219=$ \\
\hline 16177_1 & $\mathrm{C} 671 \mathrm{~T}$ & Homozygote & A224V \\
\hline 4610_1 & G691A & Heterozygote & G231S \\
\hline 3158_1 & G699A & Homozygote & $E 233=$ \\
\hline 6465_1 & G736A & Heterozygote & V246M \\
\hline 9172_1 & G755A & Heterozygote & G252D \\
\hline 2983_1 & G846A & Homozygote & Q282= \\
\hline 16204_1 & C861T & Heterozygote & D287= \\
\hline 13675_1 & C864T & Homozygote & $\mathrm{H} 288=$ \\
\hline 14226_1 & G1221A & Heterozygote & D365N \\
\hline 15112_1 & $\mathrm{C} 1251 \mathrm{~T}$ & Homozygote & L375= \\
\hline 10971_1 & G1289A & Heterozygote & R387= \\
\hline 11186_1 & G1314A & Homozygote & V396M \\
\hline 11295_1 & G1319A & Heterozygote & G397= \\
\hline 15186_1 & G1332A & Heterozygote & V402I \\
\hline 10869_1 & C1365T & Homozygote & L413F \\
\hline 10498_1 & C1389T & Homozygote & $L 421=$ \\
\hline 8989_1 & C1460T & Heterozygote & $\mathrm{G} 444=$ \\
\hline 10895_1 & C1464T & Heterozygote & L446F \\
\hline 4786_1 & C1471T & Heterozygote & P448L \\
\hline 15867_1 & C1511T & Heterozygote & $\mathrm{T} 461=$ \\
\hline 7736_1 & G1566A & Heterozygote & A480T \\
\hline 13507_1 & G1569A & Homozygote & G481R \\
\hline 15012_1 & G1642A & Homozygote & S505N \\
\hline 13490_1 & G1651A & Heterozygote & G508E \\
\hline 13955_1 & C1678T & Heterozygote & A517V \\
\hline 14646_1 & C1707T & Heterozygote & $L 527=$ \\
\hline 14033_1 & C1724T & Homozygote & S532= \\
\hline 10243_1 & C1748T & Heterozygote & $N 540=$ \\
\hline
\end{tabular}

${ }^{a}$ Coordinates based on genomic sequence of cv. Barke.

${ }^{\mathrm{b}}$ Amino acid changes are given given as positions in protein sequence of $\mathrm{cv}$. Barke. Stop codons are indicated by ' ${ }^{* \prime}$ ', synonymous changes by ' $=$ '.

identified through BLAST searches against the sequence resources integrated to the physical map of barley [23] two fingerprinted contigs, contig_45097 and contig_ 46058, which harbored two genes whose orthologs in
Brachypodium were the closest neighbors of the ortho$\log$ of MND, as well as the co-segregating and a distal flanking markers M4 and M5. Likewise, contig_1020 was found to harbor marker M3, flanking MND in proximal direction. We found no BAC sequences with high similarity to MND. This is not unexpected as only $1.1 \mathrm{~Gb}$ of genomic sequence information (approximately 20\% of the barley genome) is directly provided by the physical map of barley $(6,278$ sequenced BAC clones, BAC end sequences) [23]. However, a BAC harboring MND and assigned to fingerprinted contig_45097 was identified through BAC library screening.

Next, we assembled the MTPs of these three physical contigs (Figure 6a) by sequencing 38 BACs (Figure 6b; Additional file 7: Table S5) on the Illumina HiSeq2000. Single BACs were assembled to 'phase-1' quality, that is, unordered contig sequences. All-against-all BLAST searches of BAC assemblies confirmed the contiguity of contigs 46058 and 45097 as well as the overlap between them. Contig_1020 did not overlap with either of them. Markers M4 and M5 were located on a contiguous sequence scaffold, which enabled to us to estimate an approximate ratio between physical and genetic distance at the MND locus of approximately $740 \mathrm{~kb}$ per cM.

In the following step, gene models (Figure 6c) were predicted on repeat masked BAC assemblies by using an $a b$ initio method and through alignment of gene models defined on the Morex WGS assembly [23]. Overall, 98 non-redundant gene models were defined on the BAC sequences. Twenty-five genes were found by both methods, 35 were only predicted $a b$ initio and likely represent pseudogenes. Thirty-eight genes were included only in the IBSC annotation, the majority (23 genes) of them classified as low confidence transcripts, which are also putative pseudogenes or gene fragments. Gene order was largely collinear to Brachypodium with some minor rearrangements (Figure 6c). Synteny enabled us to orient contig_1020 relative to the other two contigs.

Finally, we attempted to estimate the size of the gap that was remaining between fingerprinted contigs 1020 and 45097 and to find additional BACs that may bridge it. As 10 Brachypodium genes between Bradi4g 35770 and Bradi4g35860 are missing, the gap between contigs 1020 and 45097 may size up to several hundred kilobases, or the gap is small and may represent a region with lack of collinearity between barley and Brachypodium. We linked WGS contigs carrying the barley orthologs of the 'missing' Brachypodium genes to end sequences of BACs that were part of two short physical contigs (45219 and 45903) of sizes 227 and $236 \mathrm{~kb}$ (Table 4). These contigs carry the orthologs of Bradi4g35840 and Bradi4g35800, further supporting overall collinearity with Brachypodium in this genomic region. Moreover, one BAC end sequence (HF198106) pertaining to contig_45219 matched with 

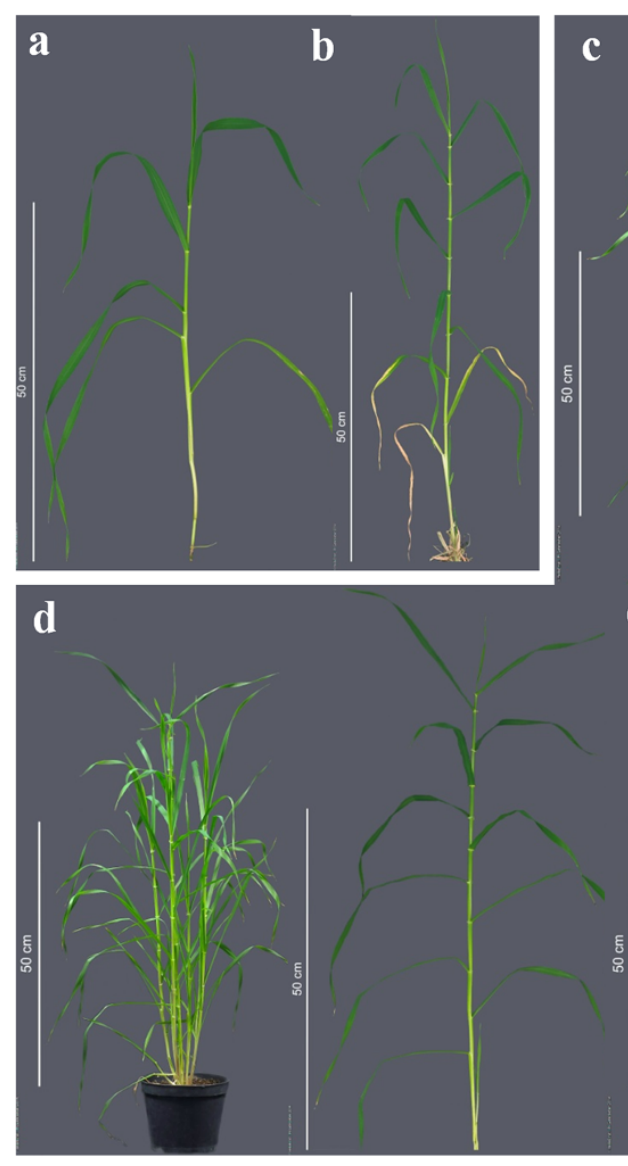

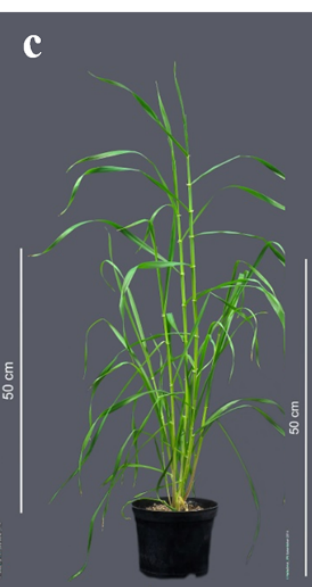

e
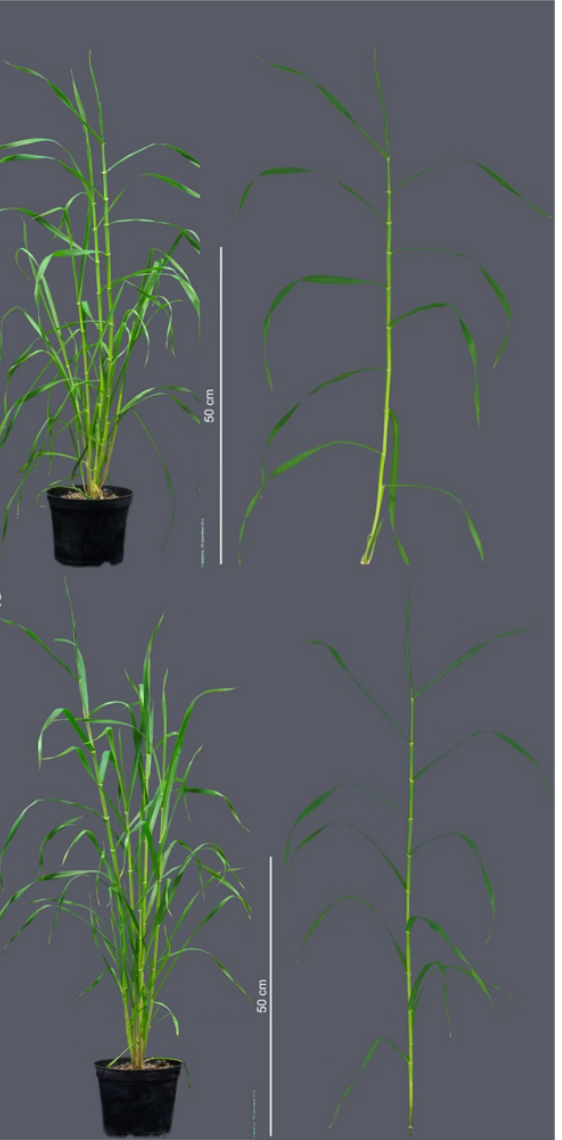

Figure 3 mnd mutants. TILLING mutants (b) with a premature stop codon within the MND genes show a significantly faster leaf initiation compared to the wildtype (a). mnd mutants in the same genetic background (cv. Kristina) with a single amino acid change (c), a complete gene deletion (d), and a premature stop codon (e). The type of mutation did not affect the severity of the mnd phenotype under greenhouse conditions. The complete growth stature (left) and a single isolated tiller (right) is shown for each plant in (c, $\mathbf{d}$, and e).

high identity (99.9\% identity over $755 \mathrm{bp}$ ) to two BAC sequences of contigs_45097, indicating that these two FP contigs may overlap.

In summary, at the genetic resolution provided by 100 F2 plants, we were not able to obtain in one step a single physical sequence scaffold of overlapping BAC clones from the MND locus between the two closest flanking markers. However, the remaining gap may be closed by sequencing the MTP of the two additional FP contigs identified based on conserved synteny information to Brachypodium. Furthermore, increasing the genetic resolution significantly to several thousand meioses, as often required in barley, may allow to resolve recombinations between marker M4 and the MND gene, which would result in landing with flanking markers on a single BAC contig scaffold provided by the physical

Table 3 Sequence variation of MND in nearly isogenic lines of cv. Bowman [17] described as mnd

\begin{tabular}{|c|c|c|c|c|c|c|c|}
\hline Name & Allele & Chr & Mutagen & Original cultivar & Backcross & Mutation & Effect \\
\hline BW516 & mnd.f & NA & Spontaneous & UT1713 & $\mathrm{BC} 3$ & / & \\
\hline BW517 & mnd.h & NA & Fast neutron & Steptoe & $\mathrm{BC} 1$ & / & \\
\hline BW518 & mnd1.a & $4 \mathrm{HL}$ & Spontaneous & Mesa & $\mathrm{BC} 8$ & / & \\
\hline BW519 & mnd3.d & $3 \mathrm{H}$ & Gamma-ray & Montcalm & BC6 & / & \\
\hline BW520 & mnd4.e & $5 \mathrm{HL}$ & Ethyl methanesulfonate & Akashinriki $^{a}$ & BC6 & G1642A & R505K \\
\hline BW521 & mnd5.g & NA & Spontaneous & Logan/ND15053 & $\mathrm{BC} 3$ & / & \\
\hline BW522 & mnd6.6 & $5 \mathrm{HL}$ & Ethylene imine & Bonus & BC6 & Complete deletion & \\
\hline
\end{tabular}

${ }^{\mathrm{a}}$ No reference DNA of Akashinriki was available. We excluded all SNPs that were shared with cv. Morex and Barke. 


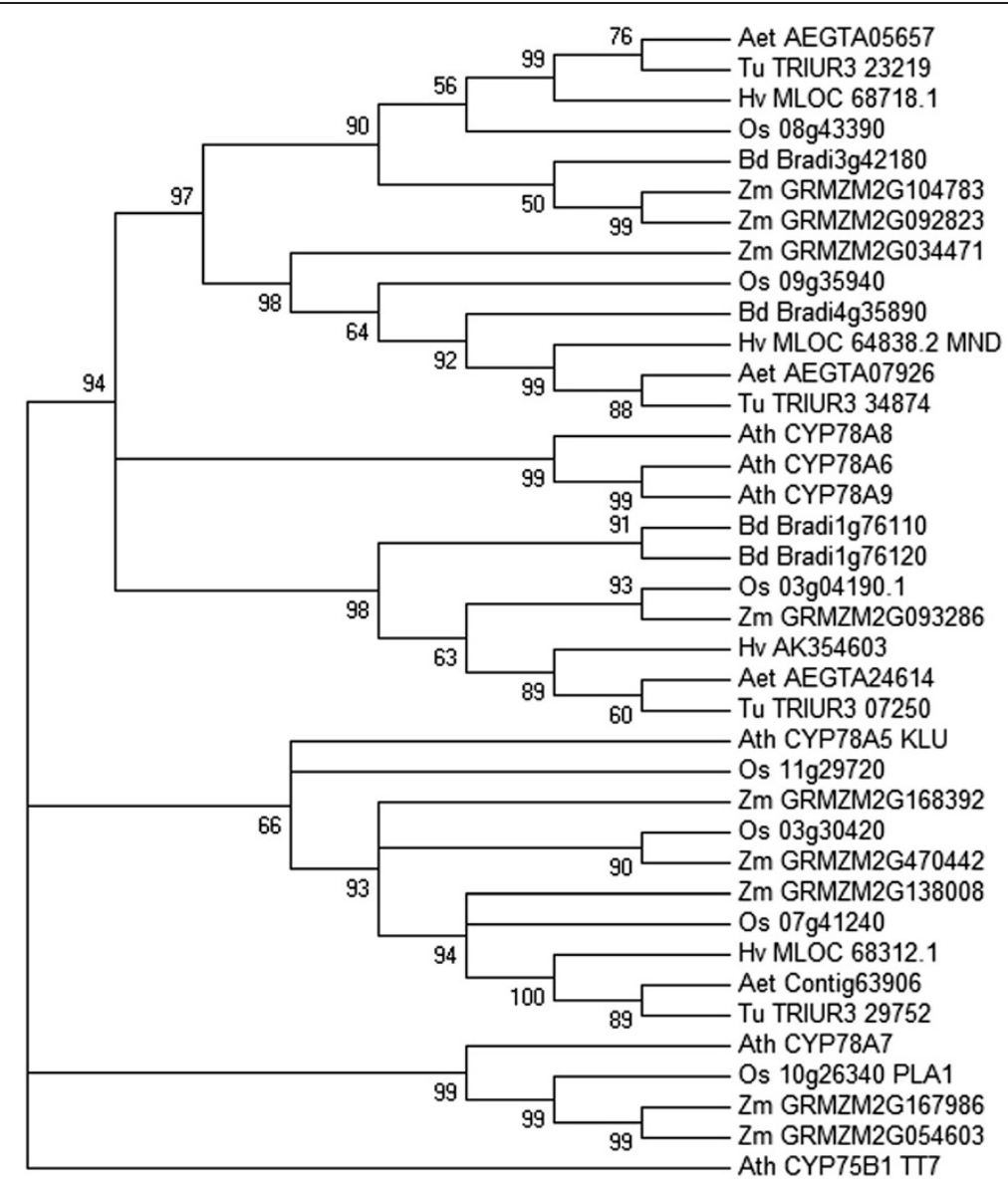

Figure 4 Phylogenetic analysis of CYP78A genes. A phylogenetic tree of 38 protein sequences of CYP78A from different species was constructed with MEGA5. Abbreviated species names are given before gene identifiers: Aegilops tauschii (Aet), A. thaliana (Ath), B. distachyon (Bd), H. vulgare (Hv), Oryza sativa (Os), T. urartu (Tu), Zea mays (Zm). Gene names are given after identifiers if available. The CYP75B1 gene TT7 of $A$. thaliana was used as an outgroup. The bootstrap method was applied to test for statistical significance of branches. The percentage of replicate trees in which the associated taxa clustered together in the bootstrap test (1,000 replicates) is shown next to the branches. Branches with insufficient bootstrap support $(<50 \%)$ were collapsed to obtain a consensus tree.

map of barley. Thus, in spite of the advanced genomic resources that are now available for barley, an iterative process involving more than one round of MTP sequencing and overlap analysis may still be required to obtain a contiguous physical map of a candidate locus.

\section{Discussion}

We have implemented mapping-by-sequencing in barley. Through sequencing two small phenotypic bulks from an $F_{2}$ mapping population of 100 individuals segregating for the $m n d$ phenotype, we were able to identify in a single sequencing experiment the deletion of a cytochrome P450 gene of the CYP78A subfamily as a likely candidate for the causal mutation. Resequencing of this candidate in other mnd mutants from several independent sources revealed a partial as well as complete deletion alleles, truncated protein products, splice site mutations and single amino acid substitutions, in summary confirming our candidate as the $M N D$ gene.

Previous mapping-by-sequencing experiments have mainly targeted EMS mutants. In rice, mappingby-sequencing has been combined with local de novo assembly to clone a resistance gene missing from the reference genome, that is, the mutant harbored an insertion relative to the reference [30]. Our results show that mapping-by-sequencing can also easily be adapted to deletion mutants obtained by X-ray or fast neutron mutagenesis, the major adjustment to the analysis procedure being the inspection of read depth instead of SNP effects on coding sequence. As we mined our sequence data, we prioritized large ( $\geq 150 \mathrm{bp}$ ) deletions. It may be necessary to relax this criterion as the spectrum of radiationinduced mutations also includes deletions of various sizes and even single base substitutions [31]. Of note, we 


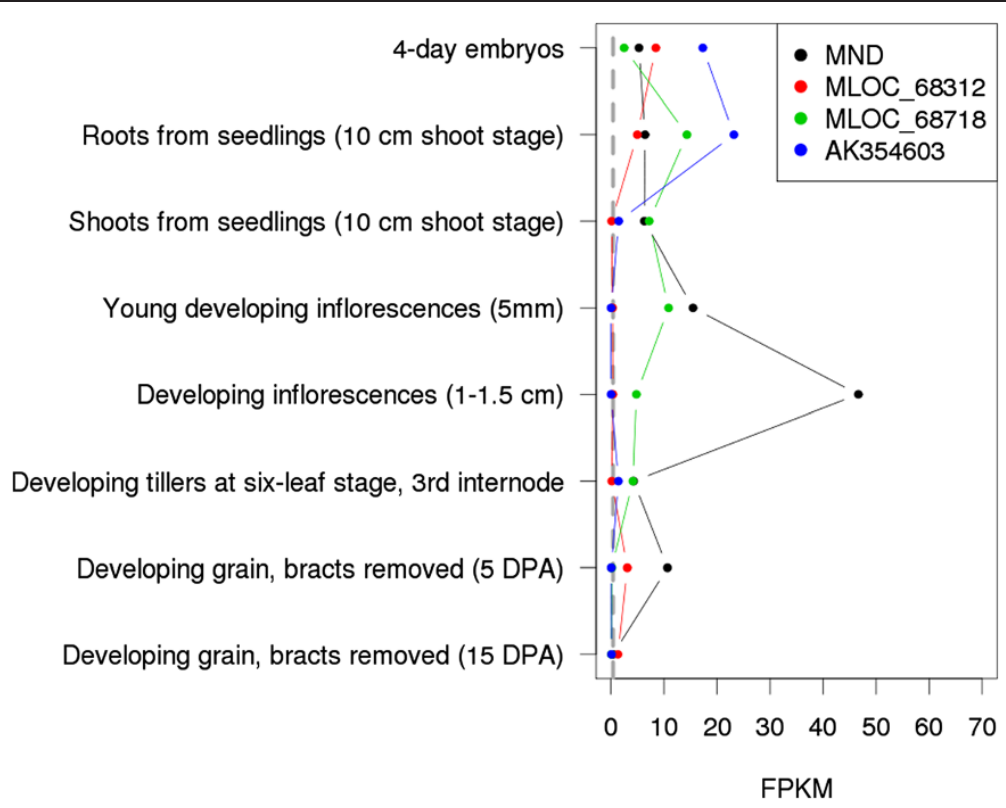

Figure 5 Expression of MND and three other CYP78A genes of barley. Transcript abundance is given as fragments per kilobase of exon per million reads mapped (FPKM) across eight different tissues or developmental stages. A gene was considered expressed if its FPKM value was above the threshold of 0.4 [23] (marked by gray line). All data were taken from [23].

could make use of an existing WGS assembly of one parent of our mapping population [23]. Otherwise, we would have used the assembly of cv. Morex as a reference for read mapping and sequenced one parent to determine its genomic background relative to Morex, similar to the procedure described in [32]. In the present study, we genotyped the individuals of our mapping population using single-marker assays developed from SNP detected in the exome sequencing data. Although these data confirmed and refined the target interval determined through mapping-by-sequencing, additional genotypic data of a mapping population are in general not necessary supplements to a mapping-by-sequencing experiment. In the present study, even a broadly defined

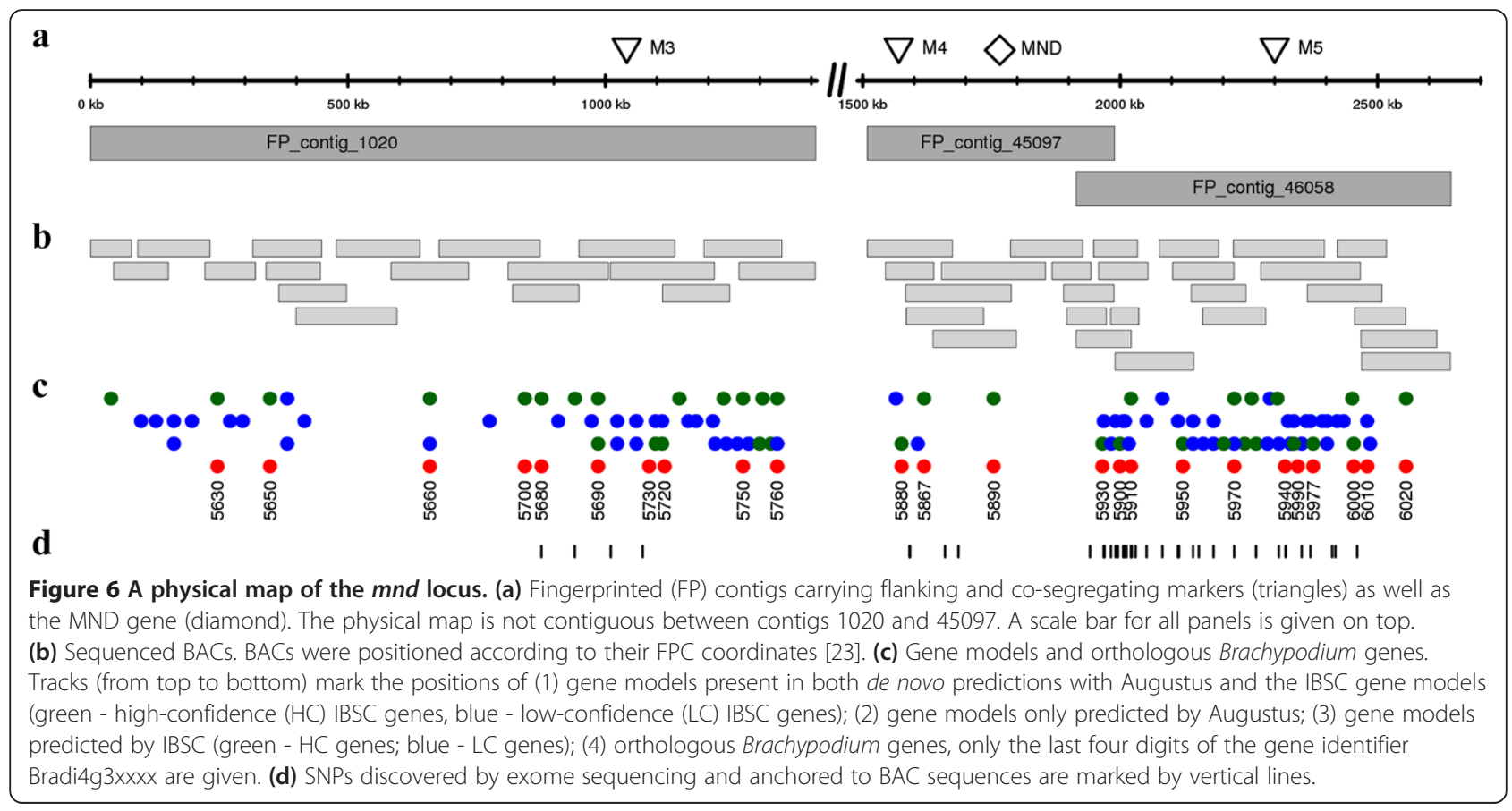


Table 4 Additional fingerprinted (FP) BAC contigs at the mnd locus

\begin{tabular}{|c|c|c|}
\hline & contig_45219 & contig_45903 \\
\hline Genetic position $^{a}$ & $5 \mathrm{H}, 97 \mathrm{cM}$ & $5 \mathrm{H}, 96 \mathrm{cM}$ \\
\hline Length & $227 \mathrm{~kb}$ & $236 \mathrm{~kb}$ \\
\hline BAC & HWMRXALLeA0202J12 & HWMRXALLhA0201C20 \\
\hline $\mathrm{BAC}$ end sequence ${ }^{\mathrm{b}}$ & HF177908 & HF089656 \\
\hline Morex WGS contigs & contig_57438 & contig_46356 \\
\hline $\begin{array}{l}\text { Barley high-confidence } \\
\text { gene }\end{array}$ & MLOC_70099.11 & MLOC_62256.1 \\
\hline $\begin{array}{l}\text { Orthologous } \\
\text { Brachypodium gene }\end{array}$ & Bradi4g35840 & Bradi4g35800 \\
\hline
\end{tabular}

${ }^{a}$ According to [29].

${ }^{\mathrm{b}}$ GenBank accession number [23].

interval of $30 \mathrm{cM}$ (5H, 80 to $110 \mathrm{cM}$ ) harbored only six deleted capture targets overlapping with high-confidence genes. Completely forgoing genetic mapping, however, for instance by only comparing read depth in sequencing for one mutant and one wildtype individuals, does not seem advisable as it would be challenging to prioritize candidates without any additional positional information.

A simulation study [33] has recently highlighted pool size, sequencing depth, and recombination frequency as key determinants of mapping resolution in mappingby-sequencing experiments. As we targeted a deletion mutant located in a highly recombinogenic subtelomeric region, even a small pool of mutant plants selected from a population of 100 plants, delimited a mapping interval small enough to clearly prioritize a single deleted region. By contrast, genes located in the genetic centromeres of barley chromosomes, where meiotic recombination is severely suppressed, are notoriously difficult to clone [34-36] and further research should investigate whether sequencing-based methods can make the rarely recombining regions accessible to positional cloning.

Sequencing depth was difficult to control in our study, as we employed exome capture to reduce the genomic complexity of DNA samples prior to sequencing. For the time being, we consider complexity reduction as a necessary evil to perform cost-efficient resequencing experiments in the large genomes of barley $(5 \mathrm{~Gb})$ or related Triticeae such as wheat (17 Gb) and rye (7 Gb). For instance, sequencing both pools to $20 \times$ whole genome coverage would have required six lanes of a Hiseq2000, while we used only one for exome sequencing. As the capture target comprises only approximately $60 \mathrm{Mb}$ of the barley gene space and has been estimated to capture approximately $75 \%$ of the sequence of high-confidence exons reliably [25], exome sequencing always incurs the risk of missing the target gene (or those parts of its sequence that contain the causal mutation). Even so, the analysis of allele frequency distribution in phenotypic bulks would always afford a sufficient number of markers to delineate genetically a target interval, which may then be analyzed in further details. If, for example, MND had not been in the capture space, we would still have been able to identify BAC contigs with closely flanking and co-segregating markers. Increasing the size of the mapping population may then have further reduced the target interval. We have not made further efforts to close gaps in the physical map between the two closest flanking markers, since the International Barley Genome Sequencing Consortium is currently sequencing the MTP of all chromosomes, so respective sequence assemblies of all BAC contigs will become available in the near future.

Mapping-by-sequencing is robust enough to tolerate some experimental error, as even a single heterozygote in the mutant pool did not prevent us from detecting the deletion of $H v M N D$. An alternative to pooled sequencing of phenotypic bulks, which confounds the identity of individual samples, is genotyping-by-sequencing (GBS) of an entire mapping population. GBS couples digestion with restriction enzymes to reduce the complexity of DNA samples with barcoded high-throughput sequencing for cost-effective multiplexed genome-wide genotyping [37,38]. As GBS, in contrast to exome capture, produces only short sequence tags and no contiguous gene sequences, the causal polymorphism is likely to be missed. For instance, absence of GBS tags in genes is no evidence for a deletion, but may simply be caused by the absence of suitable restriction sites. Consequently, GBS would necessitate follow-up experiments before a candidate can be determined with any confidence. For instance, GBS may be supplemented with whole-genome or exome sequencing of the parents of the mapping population to obtain a variation database for the design of single marker assays for further fine-mapping, or the target interval delineated by GBS may be mined for candidate genes based on an educated guess assisted by the information provided by the annotated reference assembly. A better balance between complexity reduction and multiplexing might be achievable with barcoded exome capture of an entire mapping population or selected individuals of phenotypic bulks. However, the number of samples to be processed with a single commercial exome capture kit is currently limited to 24 due to technical restrictions. A possible solution could be to combine deep multiplexing protocols [39] with exome sequencing.

A recapitulatory word of caution may not be amiss at this point. The immediate success of a mapping-bysequencing experiment, that is, pinpointing a candidate in a single step, can be hindered by many factors. Beyond an intrinsic dependence of genetic mapping on recombination rate and the degree of polymorphism between the parents of the mapping population, sequencebased methods are contingent on genomic resources. In 
barley, further complexity is added both by incomplete reference sequence information and incomplete resequencing data as a result of complexity reduction and we caution researchers adopting our strategy that they may not meet with success in as straightforward a manner as we did.

In the present study, the identification of a candidate for MND was facilitated by the previous characterization of a homolog in rice and the advantageous ratio between physical and genetic distance at the target locus $(<1 \mathrm{Mb}$ per cM). Nevertheless, we believe our result to be a showcase for what mapping-by-sequencing can achieve in the context of the current genomic framework of barley despite of its fragmentary structure. The contigs of the whole genome shotgun assembly serve, as far as read mapping is concerned, as effective surrogates for the pseudomolecules of a high-quality reference genome, because the low-copy portion of the barley gene space is reasonably well represented by them. Physical and genetic maps - occasionally assisted by synteny to the model grasses - localize these contigs with sufficient density and resolution to order the majority of sequence variants discovered through exome capture. The functional gene annotation - though mainly based on sequence similarity - is accurate enough to identify the correct gene family of MND.

MND and its rice homolog PLA1 are part of the CYP78A family of cytochrome P450 enzymes, which have been proposed to generate a novel mobile signaling compound involved in the regulation of organ size and cell proliferation of vegetative and reproductive tissue in plants [40]. The reactions catalyzed by CYP78A genes and the regulatory pathways governing their activity are largely unknown [40]. In vitro results indicated that CYP78A enzymes catalyze the hydroxylation of fatty acids [41,42]. Members of the CYP78A family may act in the same physiological pathway as ALTERED MERISTEM PROGRAM 1 (AMP1), a glutamate carboxypeptidase, whose Arabidopsis mutants show pleiotropic phenotypes such as a shortened plastochron, aberrant meristem programs, and early flowering [43]. A homolog of AMP1 in rice, PLASTOCHRON3, was also cloned as a plastochron mutant [44]. Whereas both CYP78A and AMP1 mutants of Arabidopsis and rice also exhibit an altered seed size [45-47], we did not see any effect on seed size in mnd plants (data not shown).

Phylogenetic analyses have shown that CYP78A enzymes have evolved differently in the Poaceae relative to rice and maize and suggested that MND may have taken over the functions of a lost ortholog of rice PLA1 and Arabidopsis CYP78A7. This supports the hypothesis that several CYP78A enzymes act in the same physiological pathway and may catalyze similar biochemical reactions [40]. Resolving the unknowns about the substrate(s) of
CYP78A enzymes and their upstream regulators [40] seems an attractive research goal insomuch, as the potentially beneficial effects of these genes on important agricultural traits such as the size of seeds and fruits $[47,48]$, the balance between endosperm and embryo [45] and growth stature [27] might make them valuable breeding targets if adverse effects like increased tillering can be kept to a minimum.

\section{Conclusions}

In conclusion, we have demonstrated the feasibility of mapping-by-sequencing in barley by combining reduced representation sequencing, computational analyses contextualized by comprehensive genomic resources, and mining the extensive mutant collections of barley. Similar approaches may be adopted by other map-based cloning projects in barley and in related species with large genomes, if a comparable genomic infrastructure is available for them.

\section{Materials and methods}

\section{Plant material and phenotyping}

The mnd mutant was obtained from the genebank of IPK Gatersleben (accession: MHOR474). This mutant had been induced by X-ray mutagenesis of barley cv. Saale [13]. An $F_{2}$ population was developed by crossing the mutant to $\mathrm{cv}$. Barke. One hundred $\mathrm{F}_{2}$ plants were grown to full maturation under greenhouse conditions in $2012\left(18^{\circ} \mathrm{C} / 16^{\circ} \mathrm{C}\right.$ day / night temperature). Natural light as well as additional sodium lamps were used for illumination. Twenty F3 offspring plants of each $\mathrm{F}_{2}$ individual were grown in 2013 to corroborate phenotypic scores. One half of the $\mathrm{F}_{3}$ plants were grown in pots under greenhouse conditions, the other half were grown in a nursery under field-like conditions. Plants were visually phenotyped for the number of internodes, spike length (five spikes per plant), tiller number and plant height (height of the main tiller). Plants with more than five internodes at full maturity were classified as carriers of the mnd allele. Bowman nearly-isogenic lines described as mnd [17] were obtained from the James Hutton Institute (Dundee, UK). Additionally, 37 accessions, phenotypically classified as $m n d$, were ordered from the Nordic gene bank (NordGen, Alnarp, Sweden) and cultivated under greenhouse conditions.

\section{Preparation of genomic DNA}

Plant material was harvested of young seedlings at threeleaf stage and DNA was extracted according to a modified cetyl-trimethylammonium bromide-based (CTAB) protocol of [49]. Volumes of reagents were adjusted to $1.2 \mathrm{~mL}$ to accommodate a 96-well plate format. 


\section{Exome sequencing}

DNA from 18 mutant and 30 wildtype plants was combined into two pools. Exome capture and sequencing was performed according to the protocol of [25].

\section{Read mapping and allele frequency visualization}

Reads $(2 \times 100 \mathrm{bp})$ of the mutant and wildtype pools were mapped against the whole-genome shotgun assembly of barley cv. Barke [23] with BWA [50] version 0.6.2 (commands 'aln' and 'sampe'). Single-sample SNP calling was performed for each pool with SAMtools version 0.1.18 [51]. Allele frequencies in both pools were calculated as the number of reads supporting the mutant allele divided by the number of reads at a SNP positions with a custom AWK script (Additional file 8: Text S1) and visualized along the integrated physical and genetic map of barley [23] using standard functions of the $R$ statistical environment [52]. For visualization, allele frequencies at SNP positions with at least 30-fold coverage in both pools were averaged in $1 \mathrm{cM}$ bins. SNPs with allele frequencies $\geq 80 \%$ in both pools were not considered. Only bins with at least 30 SNPs were considered. The genetic positions of sequence contigs of cv. Barke were downloaded from MIPS PlantsDB [53,54].

\section{Read depth analysis}

For coverage analysis, reads were mapped with BWAMEM 0.7.4 against the WGS assembly of barley cv. Morex as gene models and exome capture targets are only defined on the Morex assembly [23,25]. Read depth was calculated with 'samtools depth' [51]. Regions longer than 150 bp that satisfied one of the following conditions were identified using custom AWK scripts and bedtools [55]: (1) at least $5 \times$ average read depth in the wildtype pool and no read coverage in the mutant; (2) the ratio (coverage_mutant/ coverage_wildtype) was at least 4 and the coverage in the mutant pool was $\leq 2$ and $\geq 5$ in the wildtype pool. Condition (2) was chosen to tolerate a small proportion of mis-phenotyped wildtype plants in the mutant pool. The functional annotation of genes located on WGS contigs harboring such regions and the genetic positions of these contigs [23,24] were inspected. Functional annotations were downloaded from [56]. The POPSEQ positions of Morex WGS contigs were retrieved from [57]. The longest putatively deleted region (349 bp) located on a genebearing contig (morex_contig_49382 with MLOC_64838.2 annotated as 'Cytochrome P450') was assigned to the long arm of chromosome $5 \mathrm{H}$, approximately 95 to $96 \mathrm{cM}$ in the iSelect map [21] and coincided with the peaks of contrasting SNP allele frequency. MLOC_64838.2 was selected as the primary candidate for further validation. Expression data for MND and other CYP78A genes in barley was retrieved from [58].
Marker development, marker analysis, and genetic mapping SNPs derived from the exome-capture experiment were converted into CAPS markers (Additional file 3: Table S2) using SNP2CAPS software [59]. Restriction digests were performed according to manufacturer guidelines on a thermocycler. DNA fragments were separated on a $1.5 \%$ agrarose gel for genotyping. JoinMap version 4.0 (Kyazma B.V., Wageningen, The Netherlands) with Kosambi mapping function was used to construct a linkage map based on genotyping and phenotypic data.

\section{PCR amplification and Sanger sequencing}

Polymerase chain reaction (PCR) was performed on GeneAmp PCR System 9700 (Applied Biosystems, Carlsbad, CA, USA). A standardized touch down (TD-) PCR profile was used for all PCR analyses containing two cycling steps: initial denaturation for $15 \mathrm{~min}$ at $95^{\circ} \mathrm{C}$, followed by 10 cycles of denaturation at $95^{\circ} \mathrm{C} / 30 \mathrm{~s}$; annealing at $60^{\circ} \mathrm{C} / 30 \mathrm{~s}$ (decreasing by $0.5^{\circ} \mathrm{C}$ per cycle) followed by extension at $72^{\circ} \mathrm{C} / 60 \mathrm{~s}$ ); then 35 cycles denaturation at $95^{\circ} \mathrm{C} / 30 \mathrm{~s}$, annealing at $55^{\circ} \mathrm{C} / 30 \mathrm{~s}$, and extension at $72^{\circ} \mathrm{C} / 60 \mathrm{~s}$ followed by a final extension step at $72^{\circ} \mathrm{C} /$ $7 \mathrm{~min}$. PCR products were resolved by agarose gel electrophoresis using 1.5\% agarose gel (Invitrogen $\mathrm{GmbH}$, Darmstadt, Germany) strength and $1 \times \mathrm{TBE}$ buffer. A list of primers used to amplify neighboring genes of MND as inferred by synteny to $B$. distachyon is given in Additional file 3: Table S6.

PCR amplicons were purified with NucleoFast 96 ultrafiltration plates (MACHEREY-NAGEL GmbH \& Co. KG, Düren, Germany) and sequenced using BigDye ${ }^{\oplus}$ Terminator v3.1 Ready Reaction Cycle Sequencing Kit (Applied Biosystems, Carlsbad, CA, USA) on the $3730 \times 1$ DNA Analyzer (Applied Biosystems, Carlsbad, CA, USA). Obtained sequence reads were analysis was done with 'Sequencher 4' software (Genecodes Corporation, USA).

\section{Identification of mutant alleles}

We screened a TILLING population of 10,279 EMStreated plants of cv. Barke [18] to identify mutant alleles of $H v M N D$. Two Primer combinations were used to amplify the full ORF (HvMND_EX1_F/R1 and $H v M N D$ Ex2_F/R1; Additional file 3: Table S7) by using PCR with heteroduplex step as described in [18]. PCR products were digested with dsDNA Cleavage Kit and analyzed using Mutation Discovery Kit and Gel - dsDNA reagent kit on the AdvanCETM FS96 system according to manufacturer's guidelines (Advanced Analytical, IA, USA).

Three oligo combinations (HvMND_F/R1, HvMND_F/ R2, HvMND_F/R3) spanning the ORF plus intron were used to resequence the gene in independent $m$ nd accessions (Additional file 3: Table S7). Identified SNPs were confirmed by Sanger sequencing (see above). Functional 
characterization of SNPs was performed using PARSESNP software [60].

\section{BAC sequencing, assembly, and sequence analysis} A BAC harboring MLOC_64838.2 (HVVMRXALLh B0080C03, FP_contig_45097) was identified by screening a custom re-arrayed BAC library representing all clones of the minimum-tiling path of the genome-wide physical map of barley [29] by amplifying a single gene fragment (HvMND_F/R4, see Additional file 3: Table S7). Contig_ 46058 was identified as harboring flanking markers based on sequence analysis using available BAC sequences [23]. Thirty-eight BACs from these contigs were shotgunsequenced on the Illumina HiSeq2000 and assembled with CLC assembly cell version 4.0.6 [61], or on the 454 platform and assembled with MIRA [62]. In addition to MTP clones, we selected additional clones at the ends of FP contigs for sequencing to corroborate potential overlaps between BAC contigs. We also included six previously sequenced BACs [23] in the analysis (Additional file 7: Table S5). Overlap between BACs was detected by an allagainst-all alignment with megablast [63] considering only BLAST hits longer than $2 \mathrm{~kb}$ and 99.5\% sequence identity. BAC sequence contigs were subjected to k-mer-based repeat masking using the Kmasker pipeline [64]. Structural gene annotation of repeat-masked contigs was performed with Augustus [65] using the maize model. Predicted protein sequences were functionally annotated with the AHRD pipeline [66] which parses the description of BLASTP hits against the TAIR [67], Uniprot/trEMBL, and Uniprot/SwissProt [68] databases. Genes annotated as unknown proteins or transposable elements were excluded from further analysis. Gene-bearing Morex WGS contigs were aligned against the BAC assembly with megablast [63] considering only hits longer than $500 \mathrm{bp}$ and a minimum sequence identity of $99.5 \%$ to assign IBSC gene models [23] to BACs. Transcript sequences of Augustus models and IBSC genes were clustered with CAP3 [69] to collapse gene models on overlapping $\mathrm{BAC}$ clones and to link $a b$ initio models to genes in the IBSC annotation.

\section{Phylogenetic analyses}

BLASTP searches [70] against databases of barley [71], A. thaliana [72], rice [73], maize, B. distachyon [74], Ae. tauschii [75], and T. urartu [76] proteins were performed to identify CYP78A homologs of MND in these species. A phylogenetic tree was generated with MEGA5 [77] following the protocol of [78]. The evolutionary history was inferred by using the Maximum Likelihood method based on the JTT matrix-based model [79]. The bootstrap consensus tree inferred from 1,000 replicates [80] was taken to represent the evolutionary history of the taxa analyzed. Branches corresponding to partitions reproduced in less than 50\% bootstrap replicates were collapsed. Initial trees for the heuristic search were obtained by applying the Neighbor-Joining method to a matrix of pairwise distances estimated using a JTT model. A discrete Gamma distribution was used to model evolutionary rate differences among sites (5 categories $(+\mathrm{G}$, parameter $=1.5089)$ ). The analysis involved 38 amino acid sequences. All positions with less than $80 \%$ site coverage were eliminated. That is, fewer than $20 \%$ alignment gaps, missing data, and ambiguous bases were allowed at any position. There were a total of 411 positions in the final dataset.

\section{Data access}

Illumina exome sequencing data of two phenotypic pools and BAC sequencing raw data have been deposited at EMBL-ENA as accessions PRJEB5319 (exome capture) and PRJEB5363 (BACs). BAC assemblies are available from GenBank (for accession number see Additional file 7: Table S5). Sanger resequencing data is available at EMBLENA (accessions: HG965223 - HG965231).

\section{Additional files}

Additional file 1: Figure S1. Measurements of plant height, ear length, number of tillers, and number of nodes in 50 wildtype and 50 mutant plants from segregating $F_{3}$ families.

Additional file 2: Figure S2. Workflow for exome capture, sequence analysis, and genetic mapping.

Additional file 3: Table S2. CAPS markers used for genetic mapping. Table S6. Oligonucleotide used to test for complete gene deletions in neighboring genes. Table S7. Oligonucleotides used for resequencing and TILLING.

Additional file 4: Table S3. List of putative deletions.

Additional file 5: Table S1: Detected SNPS with genetic anchoring information and allele frequencies in mutant and wildtype pool.

Additional file 6: Table S4. List of resequenced accessions of the Nordic Gene Bank.

Additional file 7: Table S5. List of sequenced BACs.

Additional file 8: Text S1. AWK script to calculate allele frequency. Usage information is contained within the file.

Competing interests

The authors declare that they have no competing interests.

\section{Authors' contributions}

MM performed sequence analysis and drafted the manuscript. MJ performed experiments and helped draft the manuscript. JEK, AH, and AA performed experiments. SB performed BAC assembly. US contributed analysis tools. AG and NS designed research and helped draft the manuscript. All authors read and approved the final manuscript.

\section{Acknowledgements}

We gratefully acknowledge the skillful technical assistance of Mary Ziems, Manuela Knauft, Jacqueline Pohl, Jelena Perovic, and Heike Ernst. We thank Doreen Stengel for sequence data submission. We greatly acknowledge Arnis Druka, James Hutton Institute, Dundee for providing seeds of the BW introgression lines and Nordic Genetic Resource Center, Alnarp, Sweden for proving seeds of the mnd accessions hosted at NordGen. Our research was supported by the German Federal Ministry of Research and Education (BMBF) in frame of the NuGGET project (grant \#0315957A to NS und US). 
Received: 21 February 2014 Accepted: 10 June 2014

Published: 10 June 2014

\section{References}

1. Huang $X$, Han B: Natural variations and genome-wide association studies in crop plants. Annu Rev Plant Biol 2013, 65:531-551.

2. Michael TP, Jackson S: The first 50 plant genomes. Plant Genome 2013, 6: doi:10.3835/plantgenome2013.03.0001 in.

3. Schneeberger $K$, Weigel D: Fast-forward genetics enabled by new sequencing technologies. Trends Plant Sci 2011, 16:282-288.

4. Michelmore RW, Paran I, Kesseli RV: Identification of markers linked to disease-resistance genes by bulked segregant analysis: a rapid method to detect markers in specific genomic regions by using segregating populations. Proc Natl Acad Sci U S A 1991, 88:9828-9832.

5. Schneeberger K, Ossowski S, Lanz C, Juul T, Petersen AH, Nielsen KL, Jorgensen JE, Weigel D, Andersen SU: SHOREmap: simultaneous mapping and mutation identification by deep sequencing. Nat Methods 2009, 6:550-551.

6. Lindner H, Raissig MT, Sailer C, Shimosato-Asano H, Bruggmann R, Grossniklaus U: SNP-Ratio Mapping (SRM): identifying lethal alleles and mutations in complex genetic backgrounds by next-generation sequencing. Genetics 2012, 191:1381-1386.

7. Hartwig B, James GV, Konrad K, Schneeberger K, Turck F: Fast isogenic mapping-by-sequencing of ethyl methanesulfonate-induced mutant bulks. Plant Physiol 2012, 160:591-600.

8. Abe A, Kosugi S, Yoshida K, Natsume S, Takagi H, Kanzaki H, Matsumura H, Yoshida K, Mitsuoka C, Tamiru M, Innan H, Cano L, Kamoun S, Terauchi R: Genome sequencing reveals agronomically important loci in rice using MutMap. Nat Biotechnol 2012, 30:174-178.

9. Liu S, Yeh CT, Tang HM, Nettleton D, Schnable PS: Gene mapping via bulked segregant RNA-Seq (BSR-Seq). PLoS One 2012, 7:e36406.

10. Leshchiner I, Alexa K, Kelsey P, Adzhubei I, Austin-Tse CA, Cooney JD, Anderson H, King MJ, Stottmann RW, Garnaas MK, Ha S, Drummond IA, Paw B, North TE, Beier DR, Goessling W, Sunyaev SR: Mutation mapping and identification by whole-genome sequencing. Genome Res 2012, 22:1541-1548.

11. Galvao VC, Nordstrom KJ, Lanz C, Sulz P, Mathieu J, Pose D, Schmid M, Weigel D, Schneeberger K: Synteny-based mapping-by-sequencing enabled by targeted enrichment. Plant J 2012, 71:517-526.

12. Nordstrom K, Albani MC, James GV, Gutjahr C, Hartwig B, Turck F, Paszkowski U, Coupland G, Schneeberger K: Mutation identification by direct comparison of whole-genome sequencing data from mutant and wild-type individuals using k-mers. Nat Biotechnol 2013, 31:325-330.

13. Scholz F, Lehmann CO: Die Gaterslebener Mutanten der Saatgerste in Beziehung zur Formenmannigfaltigkeit der Art Hordeum vulgare L. III. Die Kulturpflanze 1961, 9:230-272.

14. Ehrenberg L, Lundqvist U, Osterman S, Sparrman B: On the mutagenic action of alkanesulfonic esters in barley. Hereditas 1966, 56:277-305.

15. Gustafsson $\AA$, Hagberg A, Lundqvist U, Persson G: A proposed system of symbols for the collection of barley mutants at Svalöv. Hereditas 1969, 62:409-414.

16. Gustafsson $\AA$, Hagberg A, Persson G, Wiklund K: Induced mutations and barley improvement. Theor App/ Genet 1971, 41:239-248.

17. Druka A, Franckowiak J, Lundqvist U, Bonar N, Alexander J, Houston K, Radovic S, Shahinnia F, Vendramin V, Morgante M, Stein N, Waugh R: Genetic dissection of barley morphology and development. Plant Physiol 2011, 155:617-627.

18. Gottwald S, Bauer P, Komatsuda T, Lundqvist U, Stein N: TILLING in the two-rowed barley cultivar 'Barke' reveals preferred sites of functional diversity in the gene HvHox1. BMC Res Notes 2009, 2:258.

19. Caldwell DG, McCallum N, Shaw P, Muehlbauer GJ, Marshall DF, Waugh R: A structured mutant population for forward and reverse genetics in Barley (Hordeum vulgare L.). Plant J 2004, 40:143-150.

20. Koppolu R, Anwar N, Sakuma S, Tagiri A, Lundqvist U, Pourkheirandish M, Rutten T, Seiler C, Himmelbach A, Ariyadasa R, Youssef HM, Stein N, Sreenivasulu N, Komatsuda T, Schnurbusch T: Six-rowed spike4 (Vrs4) controls spikelet determinacy and row-type in barley. Proc Natl Acad Sci U S A 2013, 110:13198-13203.

21. Comadran J, Kilian B, Russell J, Ramsay L, Stein N, Ganal M, Shaw P, Bayer M, Thomas W, Marshall D, Hedley P, Tondelli A, Pecchioni N, Francia E, Korzun V, Walther A, Waugh R: Natural variation in a homolog of Antirrhinum
CENTRORADIALIS contributed to spring growth habit and environmental adaptation in cultivated barley. Nat Genet 2012, 44:1388-1392.

22. Schulte D, Close TJ, Graner A, Langridge P, Matsumoto T, Muehlbauer G, Sato K, Schulman AH, Waugh R, Wise RP, Stein N: The international barley sequencing consortium-at the threshold of efficient access to the barley genome. Plant Physiol 2009, 149:142-147.

23. International Barley Genome Sequencing Consortium T: A physical, genetic and functional sequence assembly of the barley genome. Nature 2012, 491:711-716.

24. Mascher M, Muehlbauer GJ, Rokhsar DS, Chapman J, Schmutz J, Barry K, Munoz-Amatriain M, Close TJ, Wise RP, Schulman AH, Himmelbach A, Mayer KFX, Scholz U, Poland JA, Stein N, Waugh R: Anchoring and ordering NGS contig assemblies by population sequencing (POPSEQ). Plant $J$ 2013, 76:718-727.

25. Mascher M, Richmond TA, Gerhardt DJ, Himmelbach A, Clissold L, Sampath D, Ayling S, Steuernagel B, Pfeifer M, D'Ascenzo M, Akhunov ED, Hedley PE, Gonzales AM, Morrell PL, Kilian B, Blattner FR, Scholz U, Mayer KF, Flavell AJ, Muehlbauer GJ, Waugh R, Jeddeloh JA, Stein N: Barley whole exome capture: a tool for genomic research in the genus Hordeum and beyond. Plant $J$ 2013, 76:494-505.

26. Nelson SL, Giver CR, Grosovsky AJ: Spectrum of X-ray-induced mutations in the human hprt gene. Carcinogenesis 1994, 15:495-502.

27. Miyoshi K, Ahn BO, Kawakatsu T, Ito Y, Itoh J, Nagato Y, Kurata N: PLASTOCHRON1, a timekeeper of leaf initiation in rice, encodes cytochrome P450. Proc Natl Acad Sci U S A 2004, 101:875-880.

28. Mayer KF, Martis M, Hedley PE, Simkova H, Liu H, Morris JA, Steuernagel B, Taudien S, Roessner S, Gundlach H, Kubaláková M, Suchánková P, Murat F, Felder M, Nussbaumer T, Graner A, Salse J, Endo T, Sakai H, Tanaka T, Itoh T, Sato K, Platzer M, Matsumoto T, Scholz U, Dolezel J, Waugh R, Stein N: Unlocking the barley genome by chromosomal and comparative genomics. Plant Cell 2011, 23:1249-1263.

29. Ariyadasa R, Mascher M, Nussbaumer T, Schulte D, Frenkel Z, Poursarebani N, Zhou R, Steuernagel B, Gundlach H, Taudien S, Felder M, Platzer M, Himmelbach A, Schmutzer T, Hedley PE, Muehlbauer GJ, Scholz U, Korol A, Mayer KF, Waugh R, Langridge P, Graner A, Stein N: A sequence-ready physical map of barley anchored genetically by two million SNPs. Plant Physiol 2013, 164:412-423.

30. Takagi H, Uemura A, Yaegashi H, Tamiru M, Abe A, Mitsuoka C, Utsushi H, Natsume S, Kanzaki H, Matsumura H, Saitoh H, Yoshida K, Cano LM, Kamoun S, Terauchi R: MutMap-Gap: whole-genome resequencing of mutant F2 progeny bulk combined with de novo assembly of gap regions identifies the rice blast resistance gene Pii. New Phytol 2013, 200:276-283.

31. Masumura K, Kuniya K, Kurobe T, Fukuoka M, Yatagai F, Nohmi T: Heavy-ioninduced mutations in the gpt delta transgenic mouse: comparison of mutation spectra induced by heavy-ion, X-ray, and gamma-ray radiation. Environ Mol Mutagen 2002, 40:207-215.

32. Laitinen RA, Schneeberger $K$, Jelly NS, Ossowski S, Weigel D: Identification of a spontaneous frame shift mutation in a nonreference Arabidopsis accession using whole genome sequencing. Plant Physiol 2010, 153:652-654.

33. James GV, Patel V, Nordstrom KJ, Klasen JR, Salome PA, Weigel D, Schneeberger K: User guide for mapping-by-sequencing in Arabidopsis. Genome Biol 2013, 14:R61.

34. Okagaki RJ, Cho S, Kruger WM, Xu WW, Heinen S, Muehlbauer GJ: The barley UNICULM2 gene resides in a centromeric region and may be associated with signaling and stress responses. Funct Integr Genomics 2013, 13:33-41.

35. Shahinnia F, Druka A, Franckowiak J, Morgante M, Waugh R, Stein N: High resolution mapping of Dense spike-ar (dsp.ar) to the genetic centromere of barley chromosome 7H. Theor Appl Genet 2012, 124:373-384.

36. Acevedo-Garcia J, Collins NC, Ahmadinejad N, Ma L, Houben A, Bednarek P, Benjdia M, Freialdenhoven A, Altmuller J, Nurnberg P, Reinhardt R, SchulzeLefert $P$, Panstruga R: Fine mapping and chromosome walking towards the Ror1 locus in barley (Hordeum vulgare L.). Theor Appl Genet 2013, 126:2969-2982.

37. Poland JA, Brown PJ, Sorrells ME, Jannink JL: Development of high-density genetic maps for barley and wheat using a novel two-enzyme genotyping-by-sequencing approach. PLoS One 2012, 7:e32253.

38. Mascher M, Wu S, Amand PS, Stein N, Poland J: Application of genotypingby-sequencing on semiconductor sequencing platforms: a comparison of genetic and reference-based marker ordering in barley. PLoS One 2013, 8:e76925. 
39. Meyer M, Kircher M: Illumina sequencing library preparation for highly multiplexed target capture and sequencing. Cold Spring Harb Protoc 2010, 2010:pdb prot5448.

40. Mizutani M, Ohta D: Diversification of P450 genes during land plant evolution. Annu Rev Plant Biol 2010, 61:291-315.

41. Imaishi H, Matsuo S, Swai E, Ohkawa H: CYP78A1 preferentially expressed in developing inflorescences of Zea mays encoded a cytochrome P450-dependent lauric acid 12-monooxygenase. Biosci Biotechnol Biochem 2000, 64:1696-1701.

42. Kai K, Hashidzume H, Yoshimura K, Suzuki H, Sakurai N, Shibata D, Ohta D: Metabolomics for the characterization of cytochromes P450-dependent fatty acid hydroxylation reactions in Arabidopsis. Plant Biotechnol 2009, 26:175-182.

43. Helliwell CA, Chin-Atkins AN, Wilson IW, Chapple R, Dennis ES, Chaudhury A: The Arabidopsis AMP1 gene encodes a putative glutamate carboxypeptidase. Plant Cell 2001, 13:2115-2125.

44. Kawakatsu T, Taramino G, Itoh J, Allen J, Sato Y, Hong SK, Yule R, Nagasawa N, Kojima M, Kusaba M, Sakakibara H, Sakai H, Nagato Y: PLASTOCHRON3/ GOLIATH encodes a glutamate carboxypeptidase required for proper development in rice. Plant J 2009, 58:1028-1040.

45. Nagasawa N, Hibara Kl, Heppard EP, Vander Velden KA, Luck S, Beatty M, Nagato Y, Sakai H: GIANT EMBRYO encodes CYP78A13, required for proper size balance between embryo and endosperm in rice. Plant J 2013, 75:592-605.

46. Fang WJ, Wang ZB, Cui RF, Li J, Li YH: Maternal control of seed size by EOD3/CYP78A6 in Arabidopsis thaliana. Plant J 2012, 70:929-939.

47. Adamski NM, Anastasiou E, Eriksson S, O'Neill CM, Lenhard M: Local maternal control of seed size by KLUH/CYP78A5-dependent growth signaling. Proc Nat Acad Sci U S A 2009, 106:20115-20120.

48. Chakrabarti M, Zhang N, Sauvage C, Munos S, Blanca J, Canizares J, Diez MJ, Schneider R, Mazourek M, McClead J, Causse M, van der Knaap E: A cytochrome $\mathrm{P} 450$ regulates a domestication trait in cultivated tomato. Proc Natl Acad Sci U S A 2013, 110:17125-17130.

49. Doyle JJ: Isolation of plant DNA from fresh tissue. Focus 1990, 12:13-15.

50. Li H, Durbin R: Fast and accurate short read alignment with BurrowsWheeler transform. Bioinformatics 2009, 25:1754-1760.

51. Li H: A statistical framework for SNP calling, mutation discovery, association mapping and population genetical parameter estimation from sequencing data. Bioinformatics 2011, 27:2987-2993.

52. The R project. [http://www.r-project.org]

53. Nussbaumer T, Martis MM, Roessner SK, Pfeifer M, Bader KC, Sharma S, Gundlach H, Spannagl M: MIPS PlantsDB: a database framework for comparative plant genome research. Nucleic Acids Res 2013, 41:D1144-D1151.

54. Anchoring information of barley WGS assemblies. [ftp://ftpmips. helmholtz-muenchen.de/plants/barley/public_data/anchoring/wgs_anc/ WGS_ANC.TXT]

55. Quinlan AR, Hall IM: BEDTools: a flexible suite of utilities for comparing genomic features. Bioinformatics 2010, 26:841-842.

56. GFF file of barley HC genes. [ftp://ftpmips.helmholtz-muenchen.de/plants/ barley/public_data/genes/barley_HighConf_genes_MIPS_23Mar12_ HumReadDesc.txt]

57. Barley POPSEQ results. [ftp://ftp.ipk-gatersleben.de/barley-popseq/]

58. Barley gene expression data. [ftp://ftpmips.helmholtz-muenchen.de/plants/ barley/public_data/expression/]

59. Thiel T, Kota R, Grosse I, Stein N, Graner A: SNP2CAPS: a SNP and INDEL analysis tool for CAPS marker development. Nucleic Acids Res 2004, 32:e5.

60. Taylor NE, Greene EA: PARSESNP: A tool for the analysis of nucleotide polymorphisms. Nucleic Acids Res 2003, 31:3808-3811.

61. CLC bio website. [www.clcbio.com]

62. Chevreux B, Wetter T, Suhai S: Genome Sequence Assembly Using Trace Signals and Additional Sequence Information. Computer Science and Biology: Proceedings of the German Conference on Bioinformatics (GCB) 1999, 99:45-56.

63. Zhang Z, Schwartz S, Wagner L, Miller W: A greedy algorithm for aligning DNA sequences. J Comput Biol 2000, 7:203-214.

64. Schmutzer T, Ma L, Pousarebani N, Bull F, Stein N, Houben A, Scholz U: Kmasker - A Tool for in silico Prediction of Single-Copy FISH Probes for the Large-Genome Species Hordeum vulgare. Cytogenet Genome Res 2014, 142:66-78.
65. Stanke M, Steinkamp R, Waack S, Morgenstern B: AUGUSTUS: a web server for gene finding in eukaryotes. Nucleic Acids Res 2004, 32:W309-W312.

66. Source code of AHRD. [https://github.com/groupschoof/AHRD]

67. Lamesch P, Berardini TZ, Li D, Swarbreck D, Wilks C, Sasidharan R, Muller R, Dreher K, Alexander DL, Garcia-Hernandez M, Karthikeyan AS, Lee CH, Nelson WD, Ploetz L, Singh S, Wensel A, Huala E: The Arabidopsis Information Resource (TAIR): improved gene annotation and new tools. Nucleic Acids Res 2012, 40:D1202-D1210.

68. UniProt C: Update on activities at the Universal Protein Resource (UniProt) in 2013. Nucleic Acids Res 2013, 41:D43-D47.

69. Huang X, Madan A: CAP3: A DNA sequence assembly program. Genome Res 1999, 9:868-877.

70. Altschul SF, Gish W, Miller W, Myers EW, Lipman DJ: Basic local alignment search tool. J Mol Biol 1990, 215:403-410.

71. 1000 Genomes Project Consortium, Abecasis GR, Auton A, Brooks LD, DePristo MA, Durbin RM, Handsaker RE, Kang HM, Marth GT, McVean GA An integrated map of genetic variation from 1,092 human genomes. Nature 2012, 491:56-65.

72. Swarbreck D, Wilks C, Lamesch P, Berardini TZ, Garcia-Hernandez M, Foerster $H$, Li D, Meyer T, Muller R, Ploetz L, Radenbaugh A, Singh S, Swing V, Tissier C, Zhang P, Huala E: The Arabidopsis Information Resource (TAIR): gene structure and function annotation. Nucleic Acids Res 2008, 36:D1009-D1014.

73. Ouyang S, Zhu W, Hamilton J, Lin H, Campbell M, Childs K, Thibaud-Nissen F, Malek RL, Lee Y, Zheng L, Orvis J, Haas B, Wortman J, Buell CR: The TIGR Rice Genome Annotation Resource: improvements and new features. Nucleic Acids Res 2007, 35:D883-D887.

74. International Brachypodium Initiative T: Genome sequencing and analysis of the model grass Brachypodium distachyon. Nature 2010, 463:763-768.

75. Jia J, Zhao S, Kong X, Li Y, Zhao G, He W, Appels R, Pfeifer M, Tao Y, Zhang $X$, Jing R, Zhang C, Ma Y, Gao L, Gao C, Spannagl M, Mayer KF, Li D, Pan S, Zheng F, Hu Q, Xia X, Li J, Liang Q, Chen J, Wicker T, Gou C, Kuang H, He G, Luo $Y$, et al: Aegilops tauschii draft genome sequence reveals a gene repertoire for wheat adaptation. Nature 2013, 496:91-95.

76. Ling HQ, Zhao S, Liu D, Wang J, Sun H, Zhang C, Fan H, Li D, Dong L, Tao Y, Gao C, Wu H, Li Y, Cui Y, Guo X, Zheng S, Wang B, Yu K, Liang Q, Yang W, Lou X, Chen J, Feng M, Jian J, Zhang X, Luo G, Jiang Y, Liu J, Wang Z, Sha Y, et al: Draft genome of the wheat A-genome progenitor Triticum urartu. Nature 2013, 496:87-90.

77. Tamura K, Peterson D, Peterson N, Stecher G, Nei M, Kumar S: MEGA5: molecular evolutionary genetics analysis using maximum likelihood, evolutionary distance, and maximum parsimony methods. Mol Biol Evol 2011, 28:2731-2739.

78. Hall BG: Building phylogenetic trees from molecular data with MEGA. Mol Biol Evol 2013, 30:1229-1235.

79. Jones DT, Taylor WR, Thornton JM: The rapid generation of mutation data matrices from protein sequences. Comput Appl Biosci 1992, 8:275-282.

80. Felsenstein J: Confidence-limits on phylogenies - an approach using the bootstrap. Evolution 1985, 39:783-791.

doi:10.1186/gb-2014-15-6-r78

Cite this article as: Mascher et al:: Mapping-by-sequencing accelerates forward genetics in barley. Genome Biology 2014 15:R78.

\section{Submit your next manuscript to BioMed Central and take full advantage of:}

- Convenient online submission

- Thorough peer review

- No space constraints or color figure charges

- Immediate publication on acceptance

- Inclusion in PubMed, CAS, Scopus and Google Scholar

- Research which is freely available for redistribution 